\title{
Mutual measures of vibration process in differentiating examined construction state
}

\author{
Mariusz Żółtowski1 ${ }^{1, *}$ \\ ${ }^{1}$ UTP University of Science and Technology, Management Department, 85-790 Fordońska 430 \\ Bydgoszcz, Poland
}

\begin{abstract}
In the article author identifies a possible bone of mutual vibration energy measuring application used in the study of standard rail, as part of a dedicated research methodology and detailed methodologies developed in many previous author studies. Theoretical analysis and practical verification of susceptibility testing measurement information complex vibration processes indicates possibilities for their use. Recognizing the need to improve methods of machines and structures testing in order to assess their degradation state - this work presents important results of the research in the verification field of the proposed measures effectiveness of mutual research bench.
\end{abstract}

\section{Introduction}

Ensure the safe and trouble-free operation of machines and structures requires a search or improvement of tools, methods and techniques for non-invasive assessment of the emergency state. A common trend in recent years is the scheme and to organize various business areas targeted for specific purposes. Ensuring repeatable perform actions leading to the intended purpose it is possible, using a variety of situations dedicated research developed methodological procedures allowing for action in various areas.

Developed in a number of author's publications [7, 9-11, 13-15] vibration research methodology dedicated to solving technical problems of discipline "building" gives useful procedures endearing research issues:

$>$ acquisition processes in the vibration tests,

$>$ processing processes by vibration. optimization algorithms,

$>$ evaluate the vibration processes relationship in models of decision-making,

$>$ sensitivity vibration parameters,

$>$ statistical inference,

$>$ visualization analysis.

The problem description and study of changes in the components destruction, materials, design and construction are carried out using the measurement of simple and complex vibration diagnostics methods based on modal analysis. An important issue here is

\footnotetext{
* Corresponding author: mazolto@utp.edu.pl
} 
the description and propagation study of useful vibration energy is already widely used in diagnostic vibration and a little less used in modal analysis methods [16-18].

In this paper the suitability test measures in the monitoring complex process of the rail connections state with the base concrete, which is associated with many problems specific railway construction. The use of composite measurements mapping the interactions measured vibration process is simpler and less subject to error than the complicated procedures simulation based on numerical methods.

\section{Mutual measures of vibration process}

Research mutual similarities processes vibration through mutual estimators allows to specify:

- interdependencies between processes,

- correlation between sources,

- compliance within one process,

- changes in the road propagation processes in the machine and structure.

Measurement processes mutual indicate a change of source or variation in the transfer passageways signal extortion and answers. For these measures may include $[1,7,13]$ :

- cross-correlation function,

- coherence function,

- transfer function,

- FRF function (Frequency Response Function).

The process of measurement of the vibration is determined from the measured numerical procedures base signal, which is the value of the measured process or the two measured signals: force and the system response to put force.

The concept of using vibration energy propagation of measurement uses the value of the mean square amplitude of dynamic directly proportional to the energy of the signal and written in the form [7]:

$$
U=\int_{0}^{T} x(t)^{2} \mathrm{~d} t
$$

A measure of the propagation efficiency of vibration energy $H$ binding force signal $x(t)$ of forcing $F(t)$ takes the form:

$$
H=\frac{\int_{0}^{T} x(t)^{2} \mathrm{~d} t}{\int_{0}^{T} F(t)^{2} \mathrm{~d} t}
$$

Due to the large range of amplitudes of vibration signals is a deliberate to use logarithmic scale for comparing the numerical values of these measures:

$$
H_{[\log ]}=\log (H)
$$

Large potential research opportunities create the analysis results described in the form of a matrix using measures built at different intervals integration or pre-processed waveforms.

The concept measures the propagation of vibration energy refer to the Parseval's theorem [7], which indicates the identity of the signal energy presented in the time and frequency domains: 


$$
\int_{-\infty}^{\infty} x(t)^{2} \mathrm{~d} t=\int_{-\infty}^{\infty}\left|X(f)^{2}\right| \mathrm{d} f
$$

It is thus possible to define the measure of vibration energy propagation also in the frequency domain, and then the equation (2) becomes:

$$
H(f)=\frac{\int_{-\infty}^{\infty}\left|X(f)^{2}\right| \mathrm{d} f}{\int_{-\infty}^{\infty}\left|F(f)^{2}\right| \mathrm{d} f}
$$

In this relationship $X(f)$ is the power spectral density of the signal force, $F(f)$ - the power spectral density of the signal force, and $f$ is the frequency in Hertz.

The essence of the measurement of input and response system for e designate of measures of mutual shown in Fig. 1.



Fig. 1. Model components present measurement metrics mutual.

The opportunities created by the presented approach allows to solve many technical problems during testing of real objects, which measure defined below each other are widely use $[3,5,7,13]$.

\subsection{Correlation function of the vibration signal}

Estimator function is a signal that can be obtained by averaging in the time domain and examining the mutual relationship between the two segments of the delayed time interval $T$. It has the following form $[16,18,19]$ :

$$
R_{u u}(\tau)=\frac{1}{T} \int_{-T}^{T} u(t, \theta) \cdot u(t+\tau, \theta) \mathrm{d} t
$$

In practical applications observation time $T$ is chosen sufficiently high so that a correlation estimator properties are independent of the integration time $T$. A prerequisite for obtaining this property is the selection of $T$, that the time was much greater than the correlation time of the process $\tau_{k}$. Defined correlation function may be in the range $(-1,1)$. A very important and convenient property of this estimate is its relationship with the power spectral density (for operational modal analysis) by Fourier transformation, because:

$$
\begin{aligned}
& R_{u u}(\tau)=\int_{-\infty}^{\infty} G_{u u}(f) \cdot \exp (2 \pi \mathrm{j} f \tau) \mathrm{d} f \\
& G_{u u}(\tau)=\int_{-\infty}^{\infty} R_{u u}(f) \cdot \exp (-2 \pi \mathrm{j} f \tau) \mathrm{d} \tau
\end{aligned}
$$


This shows that the correlation function and power spectral density are the same as if the estimators of the test process, but the area they determine is different. Therefore, some of the properties of the process can be better pinpoint the time-domain retardation $\tau$ pressure than the frequency $f$.

\subsection{Cross-correlation function}

For the purpose of examining the similarity of processes at two points of the material and check if there is only one source of vibration in Fig. 2 shows the flow pattern signal $u(t)$ of such a case.

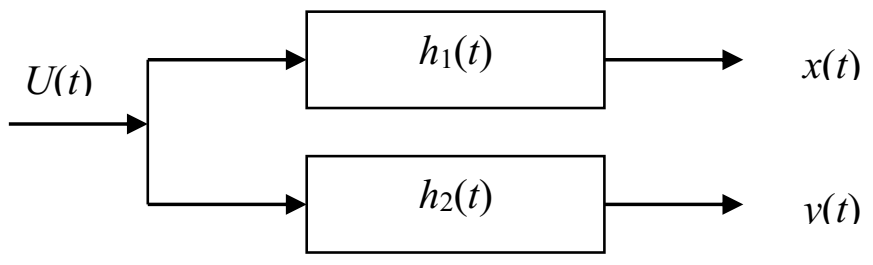

Fig. 2. Signal flow model for assessing the similarity of processes $x(t)$ and $y(t)$.

The initial process of the vibration that two different ways by the dynamic systems of the pulse transfer function $h_{1}(t), h_{2}(t)$ enters the measuring points $\mathrm{X}$ and $\mathrm{Y}$ to form new processes vibrating designated $x(t)$ and $y(t),[6,16,14]$.

The cross-correlation $R_{x y}(\tau)$, which is in the form of unor-plated should be equal to one if the signals $x(t)$ and $y(t)$ are the same, it is defined as:

$$
R_{x y}(\tau)=\frac{1}{2 T} \int_{-T}^{T} x(t) \cdot y(t+\tau) \mathrm{d} t
$$

wherein: $R_{x y}(\tau)=R_{y x}(-\tau)$, and $Q_{x y}(0)=1$ if $x(t) \rightarrow y(t)$.

In terms of diagnostic correlation function makes it possible to detect changes in signal power ratio determined for the noise interference. It is therefore a measure of the functional arrangement of these moments of the process tested. In diagnostic applications it is sometimes used to measure the delay time determining signal path and signal detection in noise and playing them.

\subsection{The coherence function}

A measure of the consistency of the two vibration processes, $x(t)$ and $y(t)$ is the coherence function defined as follows $[12,14,15]$ :

$$
\gamma_{x y}^{2}(f) \equiv \frac{\left|G_{x y}(f)\right|^{2}}{G_{x x}(f) \cdot G_{y y}(f)}
$$

Calculating the spectral density of the source of the process $x(t)$ and the known transfer function $H_{1}(f), H_{2}(f)$, we have:

$$
\begin{aligned}
& G_{x y}(f)=H_{1}(f) \cdot H_{2}(f) G_{u u}(f) \\
& G_{x x}(f)=\left[H_{1}(f)\right]^{2} G_{u u}(f) \\
& G_{y y}(f)=\left[H_{2}(f)\right]^{2} G_{u u}(f)
\end{aligned}
$$

Hence, we obtain:

$$
\gamma_{x y}^{2}(f)=\frac{\left|H_{1}(f) \cdot H_{2}(f)\right|^{2} G_{u u}^{2}(f)}{\left|H_{1}(f)\right|^{2} \cdot G_{u u}(f) \cdot\left|H_{2}(f)\right|^{2} \cdot G_{u u}(f)}=1
$$


Regardless of the nature of transmittance passageways coherence function always assumes the value 1 if only the signals $x(t)$ and $y(t)$ come from the same source. For more than one source coherence function which is a non-negative it is always less than unity $\langle 0$ $1\rangle$. The coherence function as a measure of the consistency of the two signals has good diagnostic properties, because the appearance of a new signal failure violates the consistency of the previous ones, so that coherence function decreases.

It is the local measure of similarity between signals from different sources of vibration. In practical action, measured at different times living facility, detects the appearance of defects and changes in transmittance. The function, which of the two points defines is, provides more information about the technical condition object.

\subsection{Transmittance}

The dynamic properties of linear with constant parameters can be described using a transfer function defined in the time domain or with a transmittance defined in the frequency domain. These measures fully characterize the dynamic behavior of the object (linear systems, for which it is satisfied superposition principle) and is defined as the ratio of output to input $[6,7]$.

The transformation of input to output in the time domain can be written as:

$$
y(t)=\int_{0}^{\infty} h(\tau) x(t-\tau) \mathrm{d} \tau
$$

where: $y(t), x(t)$, - input and output signals; $h(t)$ - pulse transition function.

Pulse transition function is defined as a response to the force in the form of a Dirac's pulse:

$$
y(t)=\int_{0}^{\infty} h(\tau) \delta(t-\tau) \mathrm{d} \tau=h(t)
$$

The transmittance of the frequency response is defined as:

$$
H(\mathrm{j} \bar{\omega})=\frac{Y(\mathrm{j} \bar{\omega})}{X(\mathrm{j} \bar{\omega})}
$$

where: $Y(\mathrm{j} \bar{\omega})$ - Fourier Transform output signal; $X(\mathrm{j} \bar{\omega})$ - Transform of the input signal.

Characteristic of the frequency (transmittance) is the size of the complex, $m$ and the real part and the imaginary part:

$$
H(\mathrm{j} \bar{\omega})=\operatorname{Re}\{H(\mathrm{j} \bar{\omega})\}+\operatorname{Im}\{H(\mathrm{j} \bar{\omega})\}
$$

The transfer function $H(\mathrm{j} \omega)$ and the impulse response $h(t)$ are related to a clear relationship:

$$
H(\mathrm{j} \bar{\omega})=\int_{0}^{\infty} h(\tau) \mathrm{e}^{-\mathrm{j} \bar{\omega} \tau} \mathrm{d} \tau
$$

Transmittance carries a lot of information about the behavior of the system under load. During the test masonry using transmittance are assessed changes in stiffness (real part) and damping (the imaginary part) reflecting the change in the destruction of the materials tested under varying load. 


\subsection{FRF - Frequency response function}

It is the function describing the frequency relation between the strength force $F(t)$ and the vibration acceleration $a(t)$ as the response signal measured at two points in the system under study. Spectral function of transition (FRF - Frequency Response Function) can be described as a quotient of the Fourier transform vibration exciting force $F(\omega)$, the Fourier transform of the response signal $A(\omega)$

$$
F R F=\frac{\sum F(\omega)}{\sum A(\omega)}
$$

The FRF as the main measure of experimental modal analysis is an inversion defined previously transmittance $H(f)$ and is referred to as real and imaginary parts. The method of its determination on the actual objects is shown in Fig. 3.

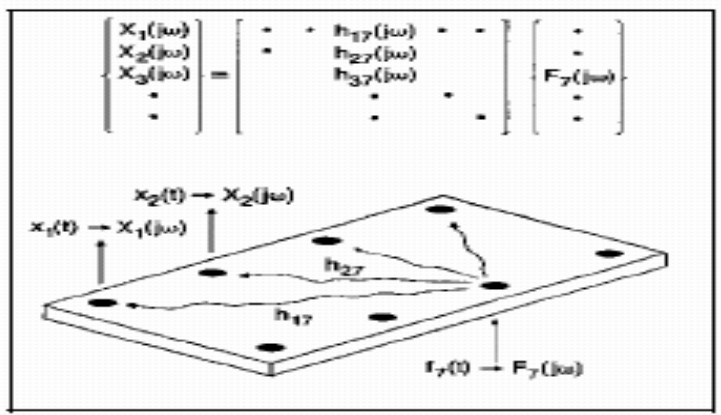

Fig. 3. Research $F R F$ facility.

The $F R F$ is a complex function of the frequency, which the module shows the characteristics of amplitude - the frequency, and the argument is the angle of the phase shift between the power of forcing a response [7, 13, 17]. The FRF is an inversion of the transmittance, which is an important observation resulting from the analysis and testing of these measures global propagation of energy.

Due to the possibility of the use of force or strength kinematic introduced different characteristics depending on the nature of the physical processes the input and output, highlighting: the vulnerability of dynamic mobility, acceleration, dynamic stiffness, impedance and dynamic mass $[4,8,10]$.

\section{Research methodology}

Verification of the indicated measures of mutual propagation of vibration energy was carried out at a laboratory in the EAFIT University of Colombia. Being investigated size vibration energy flow between the points of attachment rails to the sleepers of the track has been switched on Fig. 4. 
Point 3 :

all bold O.K

Point 4 :

bad bold: [bl]

Point 5 :

bad bold : [b1, b2]

Point 6 :

bad bolds: $[\mathrm{b} 1, \mathrm{~b} 2, \mathrm{~b} 3]$

Point 7 :

bad bolds: [b2 b4]

Point 8:

bad bold: [b4]

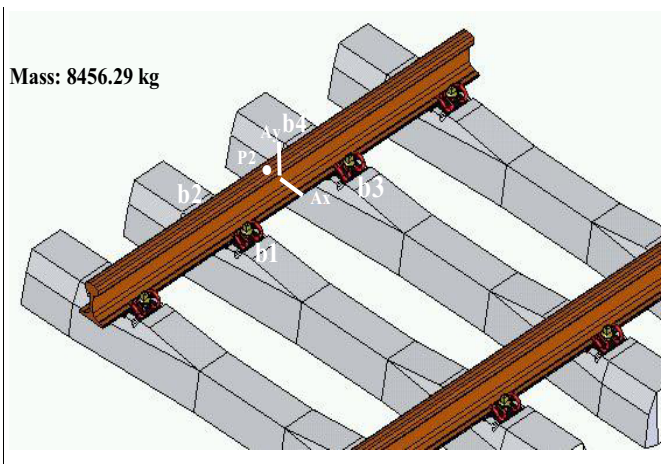

Fig. 4. Diagram of the test with the defined measuring points.

Using the studies measured vibration signals extortion and response software was set appropriate measure of each other, where the sample waveforms are shown in Fig. 5-7.
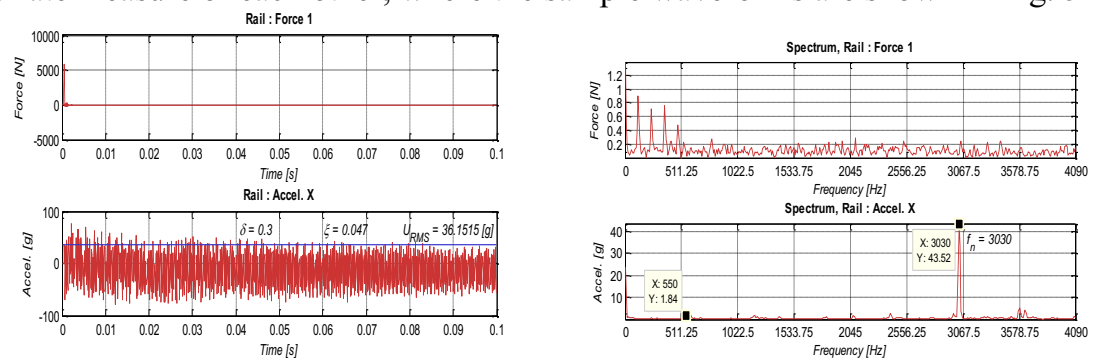

Fig. 5. Examples of the results of the exciting force and response in the time domain and frequency.


Fig. 6. The response signal and determined its coherence function.
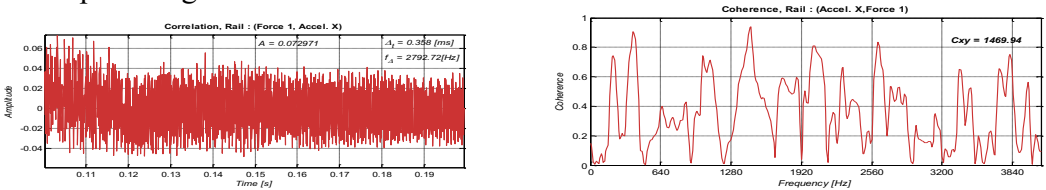

Fig. 7. Examples of waveforms transmittance and FRF.

The completed experiment studied a la the various states of attachment (pressure) between the indicated attachment points give a lot of diff s values (Table 1). 
Table 1. Results of bench studies indicated measures of mutual.

\begin{tabular}{|l|l|l|l|l|l|}
\hline $\begin{array}{l}\text { Reception } \\
\text { points }\end{array}$ & FRFr & FRFu & H(f)r & H(f)u & Cohere \\
\hline $1-2$ & 288.71 & -15.05 & 137.47 & 4.91 & 197.03 \\
\hline $2-1$ & 327.21 & 248.69 & 5.67 & 4.32 & 112.65 \\
\hline $3-4$ & 163.73 & 352.91 & -3.42 & -0.54 & 89.41 \\
\hline $4-3$ & 380.32 & -29.54 & 108,18 & 11.01 & 195.27 \\
\hline $1-3$ & 83,97 & 892.43 & -9.88 & -6.97 & 109.06 \\
\hline $1-4$ & 587.91 & -15.35 & 55.93 & 1.92 & 192.37 \\
\hline $2-3$ & 456.41 & 506.42 & 7.73 & 18.02 & 139.29 \\
\hline $4-2$ & 639.01 & -118.72 & 58.17 & 10.72 & 192.04 \\
\hline $2-4$ & $1,213.83$ & 15.03 & 17,91 & 17.99 & 125.36 \\
\hline $3-1$ & 679.94 & 157.66 & 16,34 & 11.73 & 139.08 \\
\hline $3-2$ & 985.87 & -64.41 & 39.13 & 6.75 & 183.6 \\
\hline $4-1$ & 799.05 & 38.18 & 4.55 & 24.81 & 106.61 \\
\hline
\end{tabular}

Correct inference requires redundancy of information and statistical analysis to obtain a model of bonding between the assumed technical condition and the value of mutual measures. To implement this project proposed in the work of the author's methodology dedicated research facilities in the "construction" $[1,2, .9]$ uses redundancy procedures, OPTIMUM, SVD and modeling cause - effect. The essence and the algorithm good measure of changes in the method of OPTIMUM (Fig. 8), and in the method of SVD (rys.8B) is shown in Fig. 8.

A

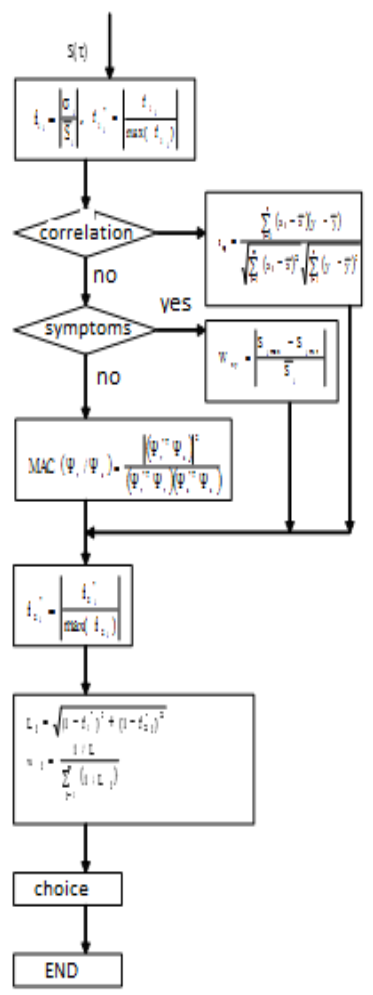

B

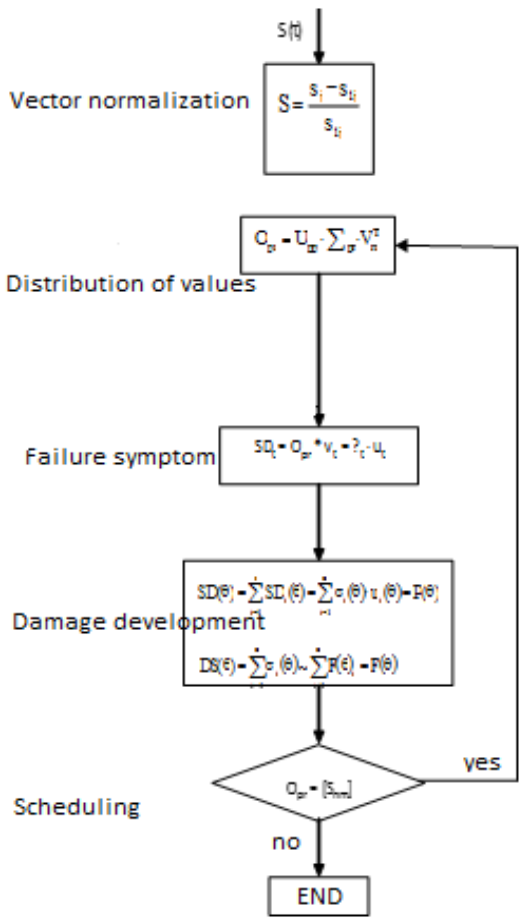

Fig. 8. Optimum algorithms for carrying out the method (A) and SVD (B). 
Examples of the results of the proposed optimization methods usefulness of measures of mutual are shown in Fig. 9.
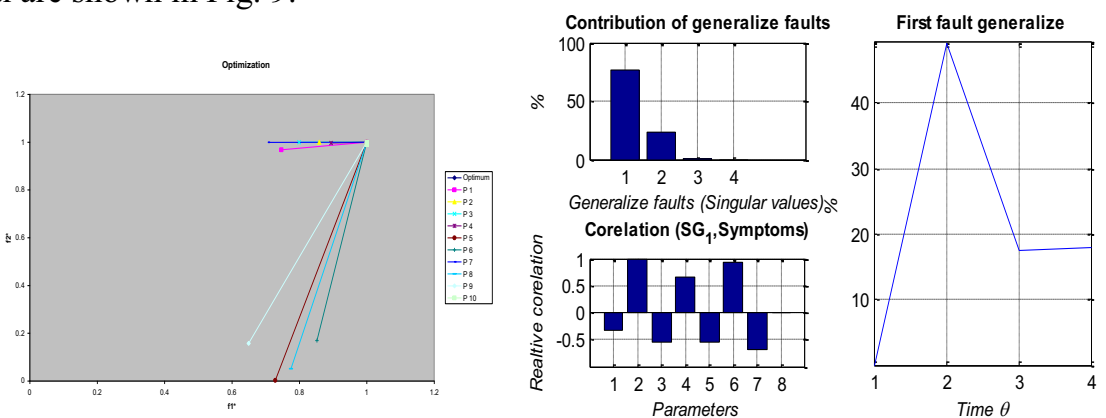

Fig. 9. The results of the OPTIMUM (A) and SVD (B) method.

Using the information contained in Table 1 processed according to the proposed methodology can confirm the good properties of measurement destruction of the cases examined the destruction of joints in order: $F R F_{r}, F R F_{u}, H(f)_{y}, H(f)_{u}$, cohere.

Taking into account all conducted a sensitivity analysis of the proposed measures of mutual propagation of vibration energy, using different statistical methods used in this work can continue to propose the following as the main measure of the state of destruction:

$F R F_{y}, H(f)_{R}$, cohere.

For the indicated reduction measures of destruction was determined regression model binding shown in Fig. 10.

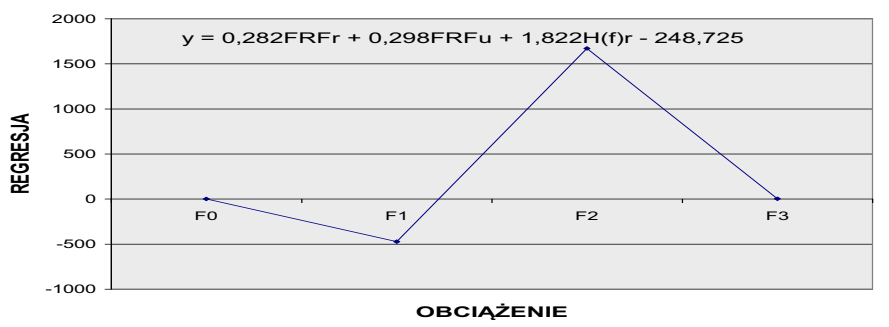

Fig. 10. Binding measures model of mutual technical connection condition.

Presented procedure is part of the proposed test method of cause - effect using various tools recommended by science literature[10, 13, 16] shown in Fig. 11.

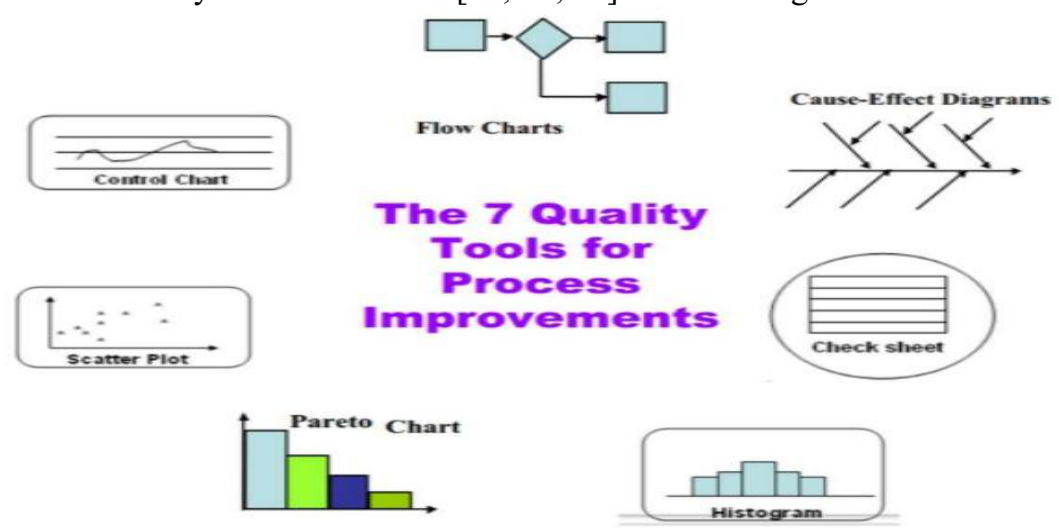

Fig. 11. Tools study of cause-effect relationships in a variety of use. 
The presented methodology of the study allows to simplify the painstaking research conducted in the field of traditional airworthy calls on the raceways, replacing the work of many service employees to maintain fitness for work programmed utilizing available information technology proposed in this study (Fig.12).

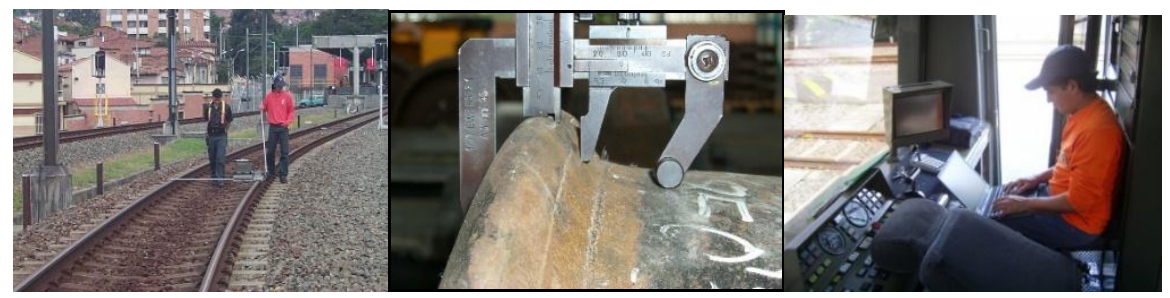

Fig. 12. The modernization work of maintenance services [4].

\section{Summary}

The substance of the development includes the results shows usefulness of mutual propagation measures of vibration energy than the various forms of applications in civil engineering. The main assumption was realized by exploratory research to present the possibilities of practical use of complex estimators vibration - as a tool to solve many fundamental problems with the condition of degradation and building construction elements dynamics.

These issues, it studies exemplify dedicated to the degradation state of the construction methodology procedure for determining the physical aspects and practical applications of propagation of vibration energy measures. The proposed methodology proceedings indicate that the important role and manner of acquisition and use of vibration composite measurements in the construction industry, revealing at the same time the need to take this issue in the area of research the destruction of existing structures. Served briefly elements of vibration theory focused on the physical aspects of the description and use of vibration estimators in the construction industry bring the issues of modeling the dynamic state of different structures and rules for their use.

Changes identification in the building structures degradation state becomes a method of assessing the structure operational status and modal analysis methods and related vibration estimates reflects well the elements and segments degradation.

New ways of obtaining and processing information contained in the processes of vibration often leads to improvement of various operating systems constructions, often leads to creative change existing practical solutions.

\section{References}

1. C. Cempel, Vibroacoustical Condition Monitoring (Ellis Ltd.New York, 1991)

2. H. Tylicki, B. Żółtowski, Rozpoznawanie stanu maszyn (ITE - PIB Radom, 2010)

3. T. Uhl, Computer-aided identification of mechanical structure models (Scientific Technical Publishers, 1997)

4. B. Żółtowski, L. Castaneda, Structural diagnosis of rail vehicles and method for redesign. Diagnostyka, 15 (2014)

5. B. Żółtowski, M. Łukasiewicz, Diagnostyka drganiowa maszy (ITE-PIB, 2012)

6. B. Żółtowski, M. Łukasiewicz, T. Kałaczyński, Techniki informatyczne $w$ badaniach stanu maszyn (UTP Bydgoszcz, 2012) 
7. B. Żółtowski, M. Żółtowski, Vibration signals in mechanical engineering and construction (ITE-PIB, 2015)

8. B. Żółtowski, C. Cempel, Engineering of diagnostics machines (PTDT, ITE - PIB, 2004)

9. M. Żółtowski, Operacyjna analiza modalna $w$ badaniach konstrukcji budowlanych (WU UTP Bydgoszcz, 2012)

10. M. Żółtowski, Informatyczne systemy zarzadzania $w$ inżynierii produkcji (ITE-PIB 2011)

11. M. Żółtowski, Investigations of harbour brick structures by using operational modal analysis. Polish Maritime Research, 21, 1, (2014)

12. M. Żółtowski, B. Żółtowski, Vibrations signal to the description of structural damage of dynamic the technical systems, XIII International Technical Systems Degradation Conference (2015)

13. M. Żółtowski, Opis drganiowy konstrukcji budowlanych. Logistyka, 6 (2014)

14. M. Żółtowski, Investigations of harbour brick structures by using operational modal analysis. Polish Maritime Research, 21, 1 (2014)

15. M. Żółtowski, M. Liss, The use of modal analysis in the evaluation of welded steel structures. Studies and Proceedings of Polish Association for Knowledge Management 79 (2016)

16. M. Żółtowski, M. Liss, Zastosowanie eksperymentalnej analizy modalnej $w$ ocenie zmian sztywności prostego elementu konstrukcyjnego. Studies and Proceedings of Polish Association for Knowledge Management, 80 (2016)

17. M. Żółtowski, R.M. Martinod, Technical Condition Assessment of Masonry Structural Components using Frequency Response Function (FRF). Masonry International Journal of the International Masonry Society, 29, 1 (2016)

18. M. Żółtowski, R.M. Martinod, Quality identification methodology applied to wallelements based on modal analysis. Civil Engineering the Athens Institute for Education and Research, Emerald, Athens (2015) 